\title{
Influence of renal insufficiency on anticoagulant effects and safety of warfarin in Chinese patients: analysis from a randomized controlled trial
}

\author{
Xiaoyi Ning $^{1} \cdot$ Yun Kuang $^{1} \cdot$ Guoping Yang $^{1,2,3} \cdot$ Jinlian Xie $^{1} \cdot$ Da Miao $^{1} \cdot$ Chengxian Guo $^{1,2,3}$ (D) Zhijun Huang $^{1,4}$
}

Received: 8 July 2020 / Accepted: 1 December 2020 / Published online: 6 January 2021

(C) The Author(s) 2021

\begin{abstract}
This study aimed to analyze the influence of renal insufficiency on the anticoagulant effects and safety of warfarin in Chinese patients. Data on the creatinine levels of participants enrolled in a randomized controlled study were screened and divided into the non-renal insufficiency group, mild renal insufficiency group, and moderate renal insufficiency group, according to the creatinine clearance rate. The primary outcome measures were stable dose and average daily dose of warfarin. Secondary outcome measures were percentage of time in the therapeutic international normalized ratio (INR) (\% TTR), and the first time to reach the therapeutic INR. Adverse events included bleeding events, thromboembolic events, and mortality. All participants with renal function test results and a baseline INR of less than 1.5 were included in the primary and secondary outcome analysis. The SPSS Statistics 21.0 software was used for statistical analysis. The randomized controlled trial was registered in Clinicaltrials.gov (NCT02211326). A total of 571 patients were included in this analysis. Multiple regression analysis showed that the renal function was correlated with stable dose, average daily dose, and the first time to reach therapeutic INR after adjusting for confounding factors. However, no correlation was noted between kidney function and \% TTR. No significant differences were observed across the various safety parameters among the three groups. Renal function is an important consideration in patients using warfarin.
\end{abstract}

Keywords Warfarin · Anticoagulants · Chronic kidney disease $\cdot$ Thromboembolism

\section{Background}

Xiaoyi Ning and Yun Kuang contributed equally to this work and should be considered joint first author

The authors confirm that the Principal Investigator for this paper is Guoping Yang and that he had direct clinical responsibility for patients.

Chengxian Guo gchxyy@163.com

$\triangle$ Zhijun Huang huangzj@csu.edu.cn

1 Center for Clinical Pharmacology, the Third Xiangya Hospital, Central South University, 138 TongZiPo Road, Changsha 410013, Hunan, China

2 Research Center for Drug Clinical Evaluation of Central South University, Changsha 410013, Hunan, China

3 Department of Pharmacy, the Third Xiangya Hospital, Central South University, Changsha 410013, Hunan, China

4 Department of Nephrology, the Third Xiangya Hospital, Central South University, Changsha 410013, Hunan, China
Warfarin is the most common and effective anticoagulant, used to prevent and treat thromboembolic disease worldwide. However, a particular challenge associated with the use of warfarin is its narrow therapeutic index with large individual variations in the daily dose requirement, often leading to either insufficient or excessive anticoagulation (Wysowski et al. 2007). Warfarin is a racemate consisting of S-warfarin and R-warfarin. S-warfarin, which exerts the main anticoagulant effect, is mainly metabolized by CYP2C9 into S-6 and S-7 hydroxyl products. R-warfarin is mainly metabolized by CYP1A2, CYP3A4, and CYP2C19 into R-8 warfarin. Warfarin is almost entirely metabolized by the liver. The hydroxyl products, which have weak anticoagulant effects, are mainly excreted by the kidney, and only a small amount of the prototype drug is excreted in the urine. Theoretically therefore, no dose adjustment of warfarin is needed in patients with chronic kidney disease (CKD). The warfarin prescribing information does not specify dosage recommendations guided by renal function. 
As a global health problem, CKD is closely related to cardiovascular disease. The prevalence of any cardiovascular disease is twice as high in patients with CKD in the USA, based on the latest kidney data system report (Usrds 2018). The prevalence of atrial fibrillation (AF) in patients with $\mathrm{CKD}$ is $12-18 \%$, including $7-8 \%$ in the general population over 65 years of age. Previous studies have shown that renal insufficiency is independently related to bleeding risk in patients with AF, who are treated with warfarin (Hirai et al. 2017; Jun et al. 2017). Renal insufficiency is also an independent risk factor in the HAS-BLED score for evaluating the bleeding risk of warfarin anticoagulation (Pisters et al. 2010). Therefore, the coexistence of high coagulation and high bleeding risk is a high risk factor in patients with CKD who also use warfarin. Previous studies have demonstrated that CKD is an independent risk factor for $\mathrm{AF}$ and is associated with a higher risk of stroke (Bonde et al. 2014).

The pathological state of renal insufficiency can affect the systemic exposure of renally eliminated drugs, which, in turn, affects the efficacy of those drugs and can lead to an increase in the number of adverse reactions. However, recent clinical studies have found that renal insufficiency affects not only the internal exposure of renally eliminated drugs but also in vivo exposure of non-renally eliminated drugs. A previous study reported a $50 \%$ increase in the plasma warfarin $\mathrm{S} / \mathrm{R}$ ratio among patients with end-stage renal disease (ESRD), compared with those without ESRD after accounting for the CYP2C9 genotype (Dreisbach et al. 2003). Another clinical study showed that CKD could inhibit the metabolism of (S)warfarin and (R, S)-warfarin (Albrecht et al. 2017).

However, as previously mentioned, no dosage recommendations in the prescribing information for warfarin have been based on renal insufficiency. Moreover, the safety and effectiveness of warfarin in patients with renal insufficiency are also controversial (Altawalbeh et al. 2018). The results of a prospective cohort study showed that in patients with AF and acute myocardial infarction, warfarin was associated with a lower 1-year risk of the composite endpoint events of mortality, myocardial infarction, and ischemic stroke in 1 year, without a higher risk of bleeding (Carrero et al. 2014). Similar findings were observed in patients with renal insufficiency, who showed event outcomes that were not associated with the degree of renal function. Another study showed that anticoagulation over the targeted international normalized ratio (INR) values is associated with a steeper decline in the estimated glomerular filtration rate and an increased frequency of CKD in patients with a mechanical prosthetic valve (Canga et al. 2018).

At present, no large randomized controlled clinical trials have been conducted to support the use of warfarin in patients with CKD. Furthermore, the existing warfarin anticoagulation guidelines for patients with CKD are derived mostly from retrospective studies. For patients with CKD, the risk- benefit ratio of warfarin needs to be carefully considered, because of the increased risk of both stroke and bleeding (Chang et al. 2019; Olesen et al. 2012; Potpara et al. 2018; Zhang et al. 2019).

Therefore, the current study, based on a prospective randomized controlled trial, analyzed the effects of renal insufficiency on anticoagulant dose and safety in Chinese patients with $\mathrm{AF}$ or deep venous thrombosis while using warfarin. The results should provide a reference for the reasonable use of warfarin in patients with CKD.

\section{Methods}

\section{Study design}

This analysis was based on a prospective randomized controlled study registered in Clinicaltrials.gov (NCT02211326) (Guo et al. 2020). Patients from 15 hospitals in China (Table S1 in Supplement 1) were recruited to participate in this multicenter, randomized, single-blind, parallel-controlled study. The study was approved by the independent ethics committee of the Third Xiangya Hospital of Central South University with an Association for the Accreditation of Human Research Protection Programs, Inc. (AAHRPP), accreditation and the independent ethics committee of each participating hospital. All participants provided written informed consent prior to the trial. Safety data were reported to and reviewed by an independent Data Safety Monitoring Board.

A flow chart of the study design is provided in Figure $\mathrm{S} 1$ in Supplement 2. Collection of relevant data and examination of routine biochemical indicators (liver and kidney function, whole blood count, urine analysis, and routine stool analysis) were performed by designated researchers at each participating hospital. The INR values were detected on a Roche Coaguchek XS system. Data were analyzed and independently confirmed by three statisticians. All researchers vouched for study protocol adherence. Genotyping for the $C Y P 2 C 9 * 2$, $C Y P 2 C 9 * 3$, and $V K O R C 1-1639 G>A$ alleles was performed using the amplification refractory mutation system (ARMS), which provided genotype results in approximately $4 \mathrm{~h}$ (Zhu et al. 2010). The genotyping of all samples was validated by Sanger sequencing.

\section{Study participants}

We recruited patients who were 18 years or older, with $\mathrm{AF}$ or deep vein thrombosis (DVT). Patients who had received previous treatment with warfarin, or who had a high bleeding risk were excluded. Furthermore, patients with a hemorrhagic tendency, who were planning to undergo an invasive examination, or surgery during the trial, and those for whom clinical judgment predicted outcomes of bleeding were also excluded. 
The detailed inclusion and exclusion criteria are presented in Table S2 in Supplement 1.

\section{Procedures}

The dosing regimen was randomly divided into genotypeguided (the first 3 days according to the IWPC [International Warfarin Pharmacogenetics Consortium] formula, the fourth to seventh days, according to the Lenzini formula (Lenzini et al. 2010), followed by adjustment by the clinician based on the INR), and clinical experience (the first 3 days 2.25 $\mathrm{mg} /$ day, followed by adjustment by the clinician based on the INR). The dosage adjustment regulations are presented in Table S3 and Table S4 in Supplement 1.

The study period was 12 weeks, with a baseline visit and eight follow-up visits as follows: -3 to -1 (baseline measurements prior to dosing); $1 ; 4 / 5 ; 8 \pm 1 ; 15 \pm 1 ; 22 \pm 1 ; 28 \pm 2 ; 57$ \pm 3 ; and $87 \pm 3$ days. Some participants had additional clinic visits and INR measurements based on clinical needs. The dosing algorithms and a detailed flow chart of follow-up visits are provided in Figure S1, included in Supplement 1.

The participants with creatinine data were screened and divided into the non-renal insufficiency group, mild renal insufficiency group, and moderate renal insufficiency group, according to the creatinine clearance rate. Renal function was graded as follows: non-renal insufficiency group, $\mathrm{CrCL}$ creatinine clearance $\geq 90 \mathrm{~mL} / \mathrm{min}$; mild renal insufficiency group, $60 \leq \mathrm{CrCL}<90 \mathrm{~mL} / \mathrm{min}$; moderate renal insufficiency, $30 \leq \mathrm{CrCL}<60 \mathrm{~mL} / \mathrm{min}$. The formula for $\mathrm{CrCL}$ was as follows: $\mathrm{CrCL}=[(140-$ age $) \times$ weight $(\mathrm{kg})] /[0.818 \times$ creatinine $(\mu \mathrm{mol} / \mathrm{L})]$ for men, and $\mathrm{CrCL}=[(140-$ age $) \times$ weight $(\mathrm{kg})] /$ $[0.818 \times$ creatinine $(\mu \mathrm{mol} / \mathrm{L})] \times 0.85$ for women .

\section{Outcome measures}

The primary outcome measures were stable dose of warfarin, defined as the dose to achieve the INR within \pm 0.1 of the therapeutic range at day 8 after dosing for 2 consecutive weeks, and the average daily dose. Secondary outcome measures were percentage of time in the therapeutic INR (\%TTR) and the first time to reach therapeutic INR. Adverse events included bleeding events (mild, moderate, or severe) (Rosendaal et al. 1993), thromboembolic events, and mortality.

\section{Statistical analysis}

All participants with renal function test results and a baseline INR of less than 1.5 were included in the primary and secondary outcome analyses. Furthermore, additional subgroup analyses for different CYP2C9 and VKORC1 genotypes were performed. Three groups were defined based on the United States Food and Drug Administration (FDA) genotype-based dosing recommendations as follows. Highly Sensitive responder: CYP $2 C 9 * 1 / 33$ and VKORC1 AA, CYP $2 C 9 * 3 / * 3$ and VKORC1 $A A$ or $G G$ or $G A$. Sensitive responder: $C Y P 2 C 9 * 1 / * 1$ and VKORC1 AA, CYP $2 C 9 * 1 / * 3$ and VKORC1 GG or GA. Normal responder: CYP2C $9^{*} 1 * 1$ and VKORC1 GG or GA.

All of the statistical indicators were selected for complete data analysis. The SPSS Statistics 21.0 software was used for statistical analysis, and the significance level was set at $P \leq$ 0.05 . Unless otherwise specified, measurement data were expressed as mean \pm SD. The Kruskal-Wallis test was applied for measurement data. Count data were expressed by direct notation or as a percentage, and the difference between groups was compared using the chi-square test, Fisher's exact test, or continuity correction chi-square test. The chi-square test was also used to evaluate test whether the frequencies of genes and alleles were consistent with Hardy-Weinberg equilibrium.

Renal function was considered an ordinal categorical variate, as follows: non-renal insufficiency group $=1$; mild renal insufficiency group $=2$; moderate renal insufficiency group $=$ 3. Multivariable analysis was used to estimate the effect of renal function on outcome variables after controlling for the confounding effects of other variables. The confounding variables included age, sex, weight, baseline INR, indications, and mode of administration. Multiple linear regression was used to analyze the continuous variables, and logistic regression was used to analyze the binary variables.

\section{Results}

\section{Participants}

We selected 571 patients with renal function results from the 660 patients in the previous randomized controlled study, and then classified them into the non-renal insufficiency group ( $n$ $=77)$, mild renal insufficiency group $(n=235)$, and moderate renal insufficiency group $(n=259)$ according to renal function. The demographics and baseline clinical characteristics of the study participants are shown in Table 1 . With the exception of age $(P<0.001)$, height $(P<0.001)$, weight $(P<0.001)$, baseline INR $(P=0.029)$, and indications $(P<0.001)$, no statistical differences were observed in other indicators. Patients with weaker renal function tended to be older, shorter, and leaner; have a higher baseline INR; and more frequently had AF than DVT. In addition, the genotypic distributions of CYP2C9 and VKORC1 conformed with Hardy-Weinberg equilibrium $(P>0.05)$.

\section{Primary outcome measure}

According to the analysis of renal function in 396 participants, the stable dose was $3.12 \pm 1.04 \mathrm{mg}$ in the non-renal insufficiency group, $2.58 \pm 0.91 \mathrm{mg}$ in the mild renal insufficiency 
Table 1 Demographic and baseline clinical characteristics of the study participants

\begin{tabular}{|c|c|c|c|c|}
\hline Index & $\begin{array}{l}\text { Non-renal } \\
\text { insufficiency } \\
\text { group } \\
(n=77) \\
(\text { Mean } \pm \text { SD) }\end{array}$ & $\begin{array}{l}\text { Mild renal insufficiency } \\
\text { group }(n=235) \\
(\text { Mean } \pm \text { SD })\end{array}$ & $\begin{array}{l}\text { Moderate renal } \\
\text { insufficiency group } \\
(n=259) \\
(\text { Mean } \pm \text { SD) }\end{array}$ & $P$ \\
\hline Age $\left(\right.$ years) ${ }^{\mathrm{a}}$ & $55.82 \pm 9.52$ & $65.17 \pm 9.07$ & $72.24 \pm 7.21$ & $\begin{array}{l}<0.0- \\
01 *\end{array}$ \\
\hline Height $(\mathrm{cm})^{\mathrm{a}}$ & $1.64 \pm 0.07$ & $1.62 \pm 0.08$ & $1.60 \pm 0.08$ & $\begin{array}{r}<0 . \\
01 *\end{array}$ \\
\hline Weight $(\mathrm{kg})^{\mathrm{a}}$ & $71.61 \pm 11.66$ & $63.82 \pm 11.06$ & $58.12 \pm 11.07$ & $\begin{array}{r}<0 . \\
01 *\end{array}$ \\
\hline Baseline INR $^{\mathrm{a}}$ & $1.02 \pm 0.11$ & $1.04 \pm 0.10$ & $1.05 \pm 0.10$ & 0.029 \\
\hline \multicolumn{5}{|l|}{ Sex, $n(\%)^{\mathrm{b}}$} \\
\hline $\begin{array}{l}\text { Male } \\
\text { Female }\end{array}$ & $\begin{array}{l}46(59.7) \\
31(40.3)\end{array}$ & $\begin{array}{l}122(51.9) \\
113(48.1)\end{array}$ & $\begin{array}{l}123(47.5) \\
136(52.5)\end{array}$ & 0.157 \\
\hline \multicolumn{5}{|l|}{ Indications, $n(\%)^{\mathrm{b}}$} \\
\hline $\begin{array}{l}\text { Atrial fibrillation } \\
\text { Deep vein thrombosis }\end{array}$ & $\begin{array}{l}56(72.7) \\
21(27.3)\end{array}$ & $\begin{array}{l}205(87.2) \\
30(12.8)\end{array}$ & $\begin{array}{l}234(90.3) \\
25(9.7)\end{array}$ & $\begin{array}{l}<0.0- \\
01 *\end{array}$ \\
\hline \multicolumn{5}{|c|}{ Mode of administration, $n(\%)^{\mathrm{b}}$} \\
\hline $\begin{array}{l}\text { Genotype-guided dosing } \\
\text { group }\end{array}$ & $45(58.4)$ & $104(44.3)$ & $133(51.4)$ & \multirow[t]{2}{*}{0.067} \\
\hline $\begin{array}{l}\text { Clinical } \\
\text { experience-guided } \\
\text { dosing group } \\
\text { Nationality, } n(\%)^{\mathrm{d}}\end{array}$ & $32(41.6)$ & $131(55.7)$ & $126(48.6)$ & \\
\hline $\begin{array}{l}\text { Han } \\
\text { Minority }\end{array}$ & $\begin{array}{l}76(98.7) \\
1(1.3)\end{array}$ & $\begin{array}{l}234(99.6) \\
1(0.4)\end{array}$ & $\begin{array}{l}259(100.0) \\
0(0.0)\end{array}$ & 0.231 \\
\hline \multicolumn{5}{|l|}{$C Y P 2 C 9, n(\%)^{\mathrm{d}}$} \\
\hline $\begin{array}{l}* 1 / * 1 \\
* 1 / * 3\end{array}$ & $\begin{array}{l}72(93.5) \\
5(6.5)\end{array}$ & $\begin{array}{l}216(91.9) \\
18(7.7)\end{array}$ & $\begin{array}{l}240(92.7) \\
18(6.9)\end{array}$ & \multirow[t]{2}{*}{0.975} \\
\hline$* 3 / * 3$ & $0(0.0)$ & $1(0.4)$ & $1(0.4)$ & \\
\hline \multicolumn{5}{|l|}{$V K O R C 1, n(\%)^{\mathrm{d}}$} \\
\hline $\begin{array}{l}A A \\
A G\end{array}$ & $\begin{array}{l}59(76.6) \\
17(22.1)\end{array}$ & $\begin{array}{l}185(78.7) \\
47(20.0)\end{array}$ & $\begin{array}{l}216(83.4) \\
39(15.1)\end{array}$ & \multirow[t]{2}{*}{0.550} \\
\hline$G G$ & $1(1.3)$ & $3(1.3)$ & $4(1.5)$ & \\
\hline \multicolumn{5}{|c|}{ Combined use of drugs, $n(\%)$} \\
\hline Fluvastatin $^{c}$ & $0(0.0)$ & $3(1.3)$ & $4(1.5)$ & 0.555 \\
\hline Amiodarone $^{\mathrm{c}}$ & $1(1.3)$ & $4(1.7)$ & $2(0.8)$ & 0.643 \\
\hline Enzyme inducer & $0(0.0)$ & $0(0.0)$ & $0(0.0)$ & 1.000 \\
\hline \multicolumn{5}{|l|}{ Co-morbidity, $n(\%)$} \\
\hline Diabetes $^{\mathrm{b}}$ & $12(15.6)$ & $36(15.3)$ & $35(13.5)$ & 0.818 \\
\hline Hypertension $^{\mathrm{b}}$ & $37(48.1)$ & $125(53.2)$ & $135(52.1)$ & 0.735 \\
\hline Apoplexy $^{c}$ & $1(1.3)$ & $11(4.7)$ & $11(4.2)$ & 0.412 \\
\hline
\end{tabular}

$* P<0.05$, with statistical significance

${ }^{\text {a }}$ Kruskal-Wallis test

${ }^{\mathrm{b}}$ Chi-square test

${ }^{\mathrm{c}}$ Continuity correction chi-square test

${ }^{\mathrm{d}}$ Fisher's exact test 
Table 2 Descriptive statistics of primary and secondary outcomes among participants with different renal functions

\begin{tabular}{|c|c|c|c|c|c|c|}
\hline \multirow[t]{2}{*}{ Measures } & \multicolumn{2}{|c|}{$\begin{array}{l}\text { Non-renal } \\
\text { insufficiency group }\end{array}$} & \multicolumn{2}{|c|}{$\begin{array}{l}\text { Mild renal } \\
\text { insufficiency group }\end{array}$} & \multicolumn{2}{|c|}{$\begin{array}{l}\text { Moderate renal } \\
\text { insufficiency group }\end{array}$} \\
\hline & $N$ & Mean \pm SD & $N$ & Mean \pm SD & $N$ & Mean \pm SD \\
\hline \multicolumn{7}{|l|}{ Primary outcomes } \\
\hline Stable dose $(\mathrm{mg})$ & 49 & $3.12 \pm 1.04$ & 173 & $2.58 \pm 0.91$ & 174 & $2.10 \pm 0.80$ \\
\hline Average daily dose $(\mathrm{mg})^{\mathrm{a}}$ & 77 & $3.21 \pm 1.09$ & 235 & $2.68 \pm 0.84$ & 259 & $2.24 \pm 0.67$ \\
\hline \multicolumn{7}{|c|}{ Secondary outcomes } \\
\hline \multicolumn{7}{|c|}{ Percentage of time in therapeutic INR range $(\% \mathrm{TTR})^{\mathrm{b}}$} \\
\hline $1-4 / 5$ days & 72 & $3.60 \pm 11.66$ & 228 & $7.98 \pm 17.38$ & 247 & $\begin{array}{r}12.96 \pm \\
21.32\end{array}$ \\
\hline $1-8$ days & 72 & $\begin{array}{r}19.83 \pm \\
22.50\end{array}$ & 222 & $\begin{array}{r}29.28 \pm \\
23.71\end{array}$ & 239 & $\begin{array}{r}35.63 \pm \\
21.88\end{array}$ \\
\hline $1-15$ days & 68 & $\begin{array}{r}36.67 \pm \\
25.78\end{array}$ & 210 & $\begin{array}{r}40.81 \pm \\
23.10\end{array}$ & 224 & $\begin{array}{r}40.64 \pm \\
21.20\end{array}$ \\
\hline $1-22$ days & 66 & $\begin{array}{r}42.90 \pm \\
28.21\end{array}$ & 206 & $\begin{array}{r}46.09 \pm \\
23.23\end{array}$ & 209 & $\begin{array}{r}44.40 \pm \\
22.53\end{array}$ \\
\hline $1-28$ days & 65 & $\begin{array}{r}46.15 \pm \\
28.06\end{array}$ & 202 & $\begin{array}{r}50.63 \pm \\
23.62\end{array}$ & 206 & $\begin{array}{r}48.01 \pm \\
22.53\end{array}$ \\
\hline 1-57 days & 63 & $\begin{array}{r}47.85 \pm \\
29.60\end{array}$ & 194 & $\begin{array}{r}57.40 \pm \\
25.18\end{array}$ & 203 & $\begin{array}{r}57.45 \pm \\
24.00\end{array}$ \\
\hline $1-87$ days & 59 & $\begin{array}{r}49.26 \pm \\
27.93\end{array}$ & 186 & $\begin{array}{r}59.56 \pm \\
25.13\end{array}$ & 190 & $\begin{array}{r}61.64 \pm \\
24.91\end{array}$ \\
\hline The first time to reach therapeutic INR & 68 & $\begin{array}{r}11.87 \pm \\
14.39\end{array}$ & 215 & $7.27 \pm 6.89$ & 239 & $5.63 \pm 3.51$ \\
\hline
\end{tabular}

${ }^{\text {a }}$ Average daily dose = total dose during the follow-up period/total follow-up days

${ }^{\mathrm{b}} \%$ TTR was calculated by linear interpolation and cubic spline interpolation

$I N R$, international normalized ratio; \%TTR, percentage of time in therapeutic INR group, and $2.10 \pm 0.80 \mathrm{mg}$ in the moderate renal insufficiency group (Table 2). Multiple regression analysis showed that renal function was correlated with the stable dose after adjusting for confounding factors (Table 3 ). With increasing severity of renal insufficiency, the stable dose of warfarin required was reduced.

In addition, 571 participants received an average daily dose. The average daily dose was $3.21 \pm 1.09 \mathrm{mg}$ in the non-renal insufficiency group, $2.68 \pm 0.84 \mathrm{mg}$ in the mild

Table 3 Multiple linear regression analysis of stable dose

\begin{tabular}{llll}
\hline Covariates & Regression coefficient & Std. error & $P$ \\
\hline Intercept & 4.451 & 0.576 & $<0.001^{*}$ \\
Renal functions & -0.223 & 0.080 & $0.006^{*}$ \\
Age & -0.183 & 0.083 & $0.028^{*}$ \\
Weight & -0.016 & 0.005 & $0.003^{*}$ \\
Baseline INR & 0.018 & 0.004 & $<0.001^{*}$ \\
Sex & -0.893 & 0.444 & $0.045^{*}$ \\
Mode of administration & 0.033 & 0.095 & 0.732 \\
Indications & -0.591 & 0.130 & $<0.001^{*}$ \\
\hline
\end{tabular}

$* P<0.05$, with statistical significance

$I N R$, international normalized ratio renal insufficiency group, and $2.24 \pm 0.67 \mathrm{mg}$ in the moderate renal insufficiency group (Table 2). Multiple regression analysis showed that renal function was correlated with the average daily dose after adjusting for confounding factors (Table 4). The average daily dose in the non-renal insufficiency group was higher than that in both the mild renal insufficiency group and moderate renal insufficiency group.

\section{Secondary outcome measures}

The multivariable analysis showed no correlation between kidney function and \%TTR, whereas renal function was correlated with the first time to reach therapeutic INR (Table 5). The first time to reach therapeutic INR values in the non-renal insufficiency group, the mild renal insufficiency group, and the moderate renal insufficiency group were $20.00 \pm 15.31$ days, $10.90 \pm 12.61$ days, and $6.05 \pm 4.75$ days respectively (Table 2). The first time to reach therapeutic INR among participants with renal insufficiency was earlier than that among participants with non-renal insufficiency. Furthermore, the renal function showed a gradual decline and the first time to reach therapeutic INR was significantly reduced, with an average difference of more than 4 days among the three groups. 
Table 4 Multiple linear regression analysis of average daily dose

\begin{tabular}{llll}
\hline Covariates & Regression coefficient & Std. error & $P$ \\
\hline Intercept & 4.861 & 0.441 & $<0.001^{*}$ \\
Renal functions & -0.220 & 0.061 & $<0.001^{*}$ \\
Age & -0.036 & 0.064 & 0.577 \\
Weight & -0.016 & 0.004 & $<0.001^{*}$ \\
Baseline INR & 0.013 & 0.003 & $<0.001^{*}$ \\
Sex & -1.152 & 0.327 & $<0.001^{*}$ \\
Mode of administration & 0.057 & 0.073 & 0.433 \\
Indications & -0.414 & 0.098 & $<0.001^{*}$ \\
\hline
\end{tabular}

$* P<0.05$, with statistical significance

$I N R$, international normalized ratio

\section{Analysis of adverse events}

Adverse events were recorded throughout the study. A total of 571 participants were evaluated for safety outcome measures as follows: 77 participants from the non-renal insufficiency group, 235 participants from the mild renal insufficiency group, and 259 participants from the moderate renal insufficiency group. No significant differences were noted in overall adverse events among the three groups (Table 6). Overall, 33 bleeding events (four in the non-renal insufficiency group, 13 in the mild renal insufficiency group, and 17 in the moderate renal insufficiency group); 21 mild bleeding events (three in the non-renal insufficiency group, nine in the mild renal insufficiency group, and nine in the moderate renal insufficiency group); seven moderate bleeding events (one in the nonrenal insufficiency group, one in the mild renal insufficiency group, and five in the moderate renal insufficiency group); and five severe bleeding events (three in the mild renal insufficiency group and two in the moderate renal insufficiency group) were reported. A single mortality was reported in each of mild renal insufficiency and moderate renal insufficiency

Table 5 Multiple linear regression analysis of the first time to reach therapeutic INR

\begin{tabular}{llll}
\hline Covariates & Regression coefficient & Std. error & $P$ \\
\hline Intercept & 23.965 & 4.256 & $<0.001^{*}$ \\
Renal functions & -1.373 & 0.598 & $0.022^{*}$ \\
Age & -2.095 & 0.624 & $0.001^{*}$ \\
Weight & -0.125 & 0.039 & $0.001^{*}$ \\
Baseline INR & 0.037 & 0.033 & 0.266 \\
Sex & -5.148 & 3.198 & 0.108 \\
Mode of administration & -0.180 & 0.707 & 0.799 \\
Indications & -1.188 & 0.954 & 0.213 \\
\hline
\end{tabular}

$* P<0.05$, with statistical significance

$I N R$, international normalized ratio groups. Just one thromboembolic event was recorded in the moderate renal insufficiency group. No significant differences were noted across the various safety parameters among the three groups (Table 6).

\section{Subgroup analysis based on genotyping}

Descriptive statistics of primary outcomes in the subgroup analysis are presented in Table 7 . Renal function was correlated with the stable dose and average daily dose among sensitive responders (Tables 8 and 9). No correlations were noted among highly sensitive responders and normal responders.

The original data that support the findings of this study was provided in Supplement 2.

\section{Discussion}

The results showed that patients with weaker renal function tended to be older. Epidemiological investigation has shown that the incidence of renal insufficiency patients in China is about $10 \%$ (Zhang et al. 2008). With increasing age, renal function tends to decline and the incidence of renal insufficiency increases. So, we have adjusted for age in the multivariate analysis, and the results showed that renal function was correlated with the stable dose and average daily dose after adjusting for confounding factors including age (Table 3 and Table 4). Based on above, we consider that after eliminating the interference of age, the influence of renal function on the warfarin effect is still significant. In comparison to those with non-renal insufficiency, patients with renal insufficiency tended to be shorter in height and have higher baseline INR values; however, these differences were small and could be considered to have no clinical significance. Moreover, the proportion of patients with AF in the renal insufficiency group was higher than that in the non-renal insufficiency group. This may be because renal insufficiency is an independent risk factor for AF (Pisters et al. 2010). The genotype frequency of the patients included in the current study conformed with the Hardy-Weinberg principle, and was representative of the general population of China.

According to the analysis of renal function in 396 participants who received a stable dose, as renal insufficiency became more severe, the stable dose of warfarin required was lower. These results are consistent with those of a previous study (Limdi et al. 2010a), which also showed that, with weakening renal function, the stable dose of warfarin can be reduced, with a similar trend in the average dose. Similar statistical results were observed in the subgroup analysis among sensitive patients. Although no correlation was observed, the multiple linear regression models established among highly sensitive responders and normal responders may not be reliable, owing to the small sample size. In 
Table 6 Safety analysis

\begin{tabular}{lllll}
\hline Analysis & $\begin{array}{l}\text { Non-renal } \\
\text { insufficiency group } \\
N(\%)\end{array}$ & $\begin{array}{l}\text { Mild renal } \\
\text { insufficiency group } \\
N(\%)\end{array}$ & $\begin{array}{l}\text { Moderate renal } \\
\text { insufficiency group } \\
N(\%)\end{array}$ & $P$ \\
\hline $\begin{array}{l}\text { Adverse events related to } \\
\text { warfarin }\end{array}$ & $4(5.2)$ & $13(5.5)$ & $17(6.6)$ & 0.850 \\
$\begin{array}{l}\text { Bleeding events } \\
\text { Mild }\end{array}$ & $4(5.2)$ & $13(5.5)$ & $16(6.2)$ & 0.928 \\
$\begin{array}{l}\text { Moderate } \\
\text { Severe }\end{array}$ & $3(3.9)$ & $9(3.8)$ & $9(3.5)$ & 0.972 \\
$\begin{array}{l}\text { Deaths (included in severe } \\
\text { bleeding events) }\end{array}$ & 0 & $1(0.4)$ & $5(1.9)$ & 0.315 \\
Thromboembolism events & 0 & $3(1.3)$ & $2(0.8)$ & 0.563 \\
\hline
\end{tabular}

addition, for patients with similar renal function, as their sensitivity to warfarin is increased, the stable dose and average daily dose should be decreased, which is consistent with the findings of previous genetics studies (Kamali 2006; Limdi et al. 2010b; Zhong et al. 2012). Based on the current results, we tried to establish a dose recommendation that takes into account both genotype and renal function, which we compared with the FDA genotype-based dosing recommendations (Table S5 in Supplement 1).

Patients in the renal insufficiency group reached the treatment INR earlier than those in the non-renal insufficiency group. This shows that administration of warfarin without considering renal function could allow patients with renal insufficiency to reach the treatment INR earlier, but would likely cause large fluctuations at a later stage (the levels of INR compliance in patients with different stages of renal function are showed in Figure S2 in Supplement 1).

In the current study, the initial dose for patients in the conventional administration group was $2.25 \mathrm{mg}$. The average initial doses or predicted doses for patients in the genotype- guided administration group with different renal function states were $2.68 \pm 0.71 \mathrm{mg}$ in the non-renal insufficiency group, $2.77 \pm 0.71 \mathrm{mg}$ in the mild renal insufficiency group, and $2.59 \pm 0.73 \mathrm{mg}$ in the moderate renal insufficiency group (Table S6 in Supplement 1). It is evident that although only the genotype was considered (without consideration of renal function) for dose prediction, the predicted dose for the patients with moderate renal insufficiency was too high (predicted error $<-20 \%$, Table S6 in Supplement 1). Previous studies have shown that during warfarin anticoagulation therapy, controlling the \%TTR to above the range of 58-65\% can significantly reduce the risk of stroke and bleeding events (Connolly et al. 2008; Piccini et al. 2014; Wallentin et al. 2010, 2013).

The current study showed that with the exception of the mean \%TTR in the non-renal insufficiency group, which was lower than 58\% (49.5\%), the \% TTR of the other two groups were between 58 and $65 \%$. This suggests that overall anticoagulation was favorable. The results of epidemiological studies have shown that the global anticoagulant compliance rate for warfarin is about $50.3 \%$, and the compliance rate in
Table 7 Descriptive statistics of primary outcomes in the subgroup analysis based on genotype $^{\mathrm{a}}$

\begin{tabular}{|c|c|c|c|c|c|c|}
\hline \multirow[t]{2}{*}{ Analysis } & \multicolumn{2}{|c|}{$\begin{array}{l}\text { Non-renal } \\
\text { insufficiency group }\end{array}$} & \multicolumn{2}{|c|}{$\begin{array}{l}\text { Mild renal insufficiency } \\
\text { group }\end{array}$} & \multicolumn{2}{|c|}{$\begin{array}{l}\text { Moderate renal } \\
\text { insufficiency group }\end{array}$} \\
\hline & $N$ & Mean \pm SD & $N$ & Mean \pm SD & $N$ & Mean $\pm \mathrm{SD}$ \\
\hline \multicolumn{7}{|l|}{ Stable dose (mg) } \\
\hline Highly sensitive responder & 1 & 2.63 & 12 & $1.75 \pm 0.40$ & 9 & $1.44 \pm 1.00$ \\
\hline Sensitive responder & 39 & $3.02 \pm 1.00$ & 130 & $2.42 \pm 0.72$ & 141 & $2.02 \pm 0.64$ \\
\hline Normal responder & 9 & $3.61 \pm 1.16$ & 31 & $3.58 \pm 1.02$ & 24 & $2.86 \pm 1.07$ \\
\hline \multicolumn{7}{|l|}{ Average daily dose (mg) } \\
\hline Highly sensitive responder & 3 & $2.51 \pm 0.26$ & 16 & $1.92 \pm 0.35$ & 15 & $1.71 \pm 0.66$ \\
\hline Sensitive responder & 58 & $3.03 \pm 1.03$ & 172 & $2.51 \pm 0.63$ & 205 & $2.16 \pm 0.54$ \\
\hline Normal responder & 16 & $3.98 \pm 1.02$ & 47 & $3.57 \pm 0.97$ & 39 & $2.88 \pm 0.85$ \\
\hline
\end{tabular}

${ }^{a}$ Highly sensitive responder: CYP2C9*1/*3 and VKORC1 AA; CYP2C9*3/*3 and VKORC1 AA or GG or GA; sensitive responder: $C Y P 2 C 9 * 1 / * 1$ and $V K O R C 1 A A, C Y P 2 C 9 * 1 / * 3$ and $V K O R C 1 G G$ or $G A$; normal responder: $C Y P 2 C 9 * 1 / * 1$ and $V K O R C 1 G G$ or $G A$. 
Table 8 Multiple linear regression analysis of stable dose in sensitive responder

\begin{tabular}{llll}
\hline Covariates & Regression coefficient & Std. error & $P$ \\
\hline Intercept & 4.211 & 0.502 & $<0.001^{*}$ \\
Renal functions & -0.171 & 0.075 & $0.023^{*}$ \\
Age & -0.017 & 0.005 & $<0.001^{*}$ \\
Weight & 0.018 & 0.004 & $<0.001^{*}$ \\
Baseline INR & -0.756 & 0.382 & $0.049^{*}$ \\
Sex & -0.010 & 0.086 & 0.910 \\
Mode of administration & -0.253 & 0.075 & $0.001^{*}$ \\
Indications & -0.589 & 0.116 & $<0.001^{*}$ \\
\hline
\end{tabular}

$* P<0.05$, with statistical significance

$I N R$, international normalized ratio

China is only $36 \%$ (Oldgren et al. 2014). The current results are higher than those reported in the literature. This phenomenon could be attributed to the fact that we performed strict and frequent treatment monitoring and follow-up of patients in the previous randomized controlled trial. On the other hand, the current findings may be related to the genotype-guided administration of some of the patients in the randomized controlled trial, which may have increased the \%TTR.

A total of 33 bleeding events were reported. One mortality was reported in each of the mild renal insufficiency and moderate renal insufficiency groups. Both cases developed cerebral hemorrhage and died of increased intracranial pressure. A previous study showed a 2.5 -fold higher risk of hemorrhage among warfarin users with severe kidney impairment after accounting for genetic and clinical factors (Limdi et al. 2009). However, bleeding events in the three groups were not statistically significant in the current study. This may have been due to efficient treatment monitoring and follow-up in the previous randomized controlled trial. In addition, the current study only followed up for 3 months; thus, a shorter

Table 9 Multiple linear regression analysis of average daily dose in sensitive responder

\begin{tabular}{llll}
\hline Covariates & Regression coefficient & Std. error & $P$ \\
\hline Intercept & 4.589 & 0.388 & $<0.001^{*}$ \\
Renal functions & -0.127 & 0.057 & $0.027^{*}$ \\
Age & -0.019 & 0.004 & $<0.001^{*}$ \\
Weight & 0.011 & 0.003 & $<0.001^{*}$ \\
Baseline INR & -0.853 & 0.290 & $0.003^{*}$ \\
Sex & 0.038 & 0.066 & 0.566 \\
Mode of administration & -0.097 & 0.058 & 0.096 \\
Indications & -0.463 & 0.089 & $<0.001^{*}$ \\
\hline
\end{tabular}

$* P<0.05$, with statistical significance

$I N R$, international normalized ratio follow-up period would result in fewer observed bleeding events.

The results of the current study showed that the stable dose and average daily dose of warfarin can be gradually decreased with declining renal function. Based on the results, it is necessary to consider the renal function of patients when using warfarin.

Supplementary Information The online version contains supplementary material available at https://doi.org/10.1007/s00210-020-02037-3.

Acknowledgments We would like to thank all trial participants including patients, clinicians, investigators, technicians, and nurses.

Authors' contribution All authors contributed to the study conception and design. Drafting of the manuscript: Xiaoyi Ning, Yun Kuang, Jinlian Xie. Critical revision of the manuscript for important intellectual content: Xiaoyi Ning, Yun Kuang, Chengxian Guo, Guoping Yang, Zhijun Huang. Statistical analysis: Xiaoyi Ning, Yun Kuang. Study supervision: Chengxian Guo, Zhijun Huang. The authors declare that all data were generated in-house and that no paper mill was used.

Funding This study was supported by National Major New Drug Creation Project of China (No. 2020ZX09201-010), National Natural Science Foundation of China $(81673519,81673520)$, and International Science \& Technology Cooperation Program of China (No. 2014DFA30900).

Data availability The data that support the findings of this study will be available from the corresponding author upon request.

\section{Compliance with ethical standards}

Conflict of interest The authors declare that they have no conflict of interest.

Ethics approval Approval was obtained from the independent ethics committee of the Third Xiangya Hospital of Central South University and the independent ethics committee of each participating hospital. The procedures used in this study adhere to the tenets of the Declaration of Helsinki.

Consent to participate All participants provided written informed consent prior to the trial.

Consent for publication Not applicable.

Code availability Not applicable.

Open Access This article is licensed under a Creative Commons Attribution 4.0 International License, which permits use, sharing, adaptation, distribution and reproduction in any medium or format, as long as you give appropriate credit to the original author(s) and the source, provide a link to the Creative Commons licence, and indicate if changes were made. The images or other third party material in this article are included in the article's Creative Commons licence, unless indicated otherwise in a credit line to the material. If material is not included in the article's Creative Commons licence and your intended use is not permitted by statutory regulation or exceeds the permitted use, you will need to obtain permission directly from the copyright holder. To view a copy of this licence, visit http://creativecommons.org/licenses/by/4.0/. 


\section{References}

Albrecht D, Turakhia MP, Ries D, Marbury T, Smith W, Dillon D, Milner PG, Midei MG (2017) Pharmacokinetics of tecarfarin and warfarin in patients with severe chronic kidney disease. Thromb Haemost 117:2026-2033

Altawalbeh SM, Alshogran OY, Smith KJ (2018) Cost-utility analysis of apixaban versus warfarin in atrial fibrillation patients with chronic kidney disease. Value Health 21:1365-1372

Bonde AN, Lip GYH, Kamper AL, Hansen PR, Lamberts M, Hommel K, Hansen ML, Gislason GH, Torp-Pedersen C, Olesen JB (2014) Net clinical benefit of antithrombotic therapy in patients with atrial fibrillation and chronic kidney disease: a nationwide observational cohort study. J Am Coll Cardiol 64:2471-2482

Canga Y, Guvenc TS, Calik AN, Karatas MB, Akdeniz E, Yuksel G, Emre A (2018) Renal function in patients with mechanical prosthetic valves : long-term effects of anticoagulation and overanticoagulation with warfarin Wien Klin Wochenschr 130:436-445

Carrero JJ, Evans M, Szummer K, Spaak J, Lindhagen L, Edfors R, Stenvinkel P, Jacobson SH, Jernberg T (2014) Warfarin, kidney dysfunction, and outcomes following acute myocardial infarction in patients with atrial fibrillation. JAMA 311:919-928

Chang SH et al. (2019) Efficacy and safety of oral anticoagulants in patients with atrial fibrillation and stages 4 or 5 chronic kidney disease Am J Med

Connolly SJ et al (2008) Benefit of oral anticoagulant over antiplatelet therapy in atrial fibrillation depends on the quality of international normalized ratio control achieved by centers and countries as measured by time in therapeutic range. Circulation 118:2029-2037

Dreisbach AW, Japa S, Gebrekal AB, Mowry SE, Lertora JJ, Kamath BL, Rettie AE (2003) Cytochrome P4502C9 activity in end-stage renal disease. Clin Pharmacol Ther 73:475-477

Guo C et al (2020) Genotype-guided dosing of warfarin in Chinese adults: a multicenter randomized clinical Trial. Circ Genom Precis Med. https://doi.org/10.1161/CIRCGEN.119.002602

Hirai T, Hamada Y, Geka Y, Kuwana S, Hirai K, Ishibashi M, Fukaya Y, Kimura T (2017) A retrospective study on the risk factors for bleeding events in warfarin therapy, focusing on renal function. Eur J Clin Pharmacol 73:1491-1497

Jun M et al (2017) Warfarin initiation, atrial fibrillation, and kidney function: comparative effectiveness and safety of warfarin in older adults with newly diagnosed atrial fibrillation. Am J Kidney Dis 69:734 743

Kamali F (2006) Genetic influences on the response to warfarin. Curr Opin Hematol 13:357-361

Lenzini P, Wadelius M, Kimmel S, Anderson JL, Jorgensen AL, Pirmohamed M, Caldwell MD, Limdi N, Burmester JK, Dowd MB, Angchaisuksiri P, Bass AR, Chen J, Eriksson N, Rane A, Lindh JD, Carlquist JF, Horne BD, Grice G, Milligan PE, Eby C, Shin J, Kim H, Kurnik D, Stein CM, McMillin G, Pendleton RC, Berg RL, Deloukas P, Gage BF (2010) Integration of genetic, clinical, and INR data to refine warfarin dosing. Clin Pharmacol Ther 87:572-578

Limdi NA, Beasley TM, Baird MF, Goldstein JA, McGwin G, Arnett DK, Acton RT, Allon M (2009) Kidney function influences warfarin responsiveness and hemorrhagic complications. J Am Soc Nephrol 20:912-921. https://doi.org/10.1681/ASN.2008070802

Limdi NA et al (2010a) Warfarin dosing in patients with impaired kidney function. Am J Kidney Dis 56:823-831. https://doi.org/10.1053/j. ajkd.2010.05.023
Limdi NA, Wadelius M, Cavallari L, Eriksson N, Crawford DC, Lee MT, Chen CH, Motsinger-Reif A, Sagreiya H, Liu N, Wu AH, Gage BF, Jorgensen A, Pirmohamed M, Shin JG, Suarez-Kurtz G, Kimmel SE, Johnson JA, Klein TE, Wagner MJ, International Warfarin Pharmacogenetics Consortium (2010b) Warfarin pharmacogenetics: a single VKORC1 polymorphism is predictive of dose across 3 racial groups. Blood 115:3827-3834

Oldgren J, Healey JS, Ezekowitz M, Commerford P, Avezum A, Pais P, Zhu J, Jansky P, Sigamani A, Morillo CA, Liu L, Damasceno A, Grinvalds A, Nakamya J, Reilly PA, Keltai K, van Gelder I, Yusufali AH, Watanabe E, Wallentin L, Connolly SJ, Yusuf S, RE-LY Atrial Fibrillation Registry Investigators (2014) Variations in cause and management of atrial fibrillation in a prospective registry of 15,400 emergency department patients in 46 countries: the RE-LY Atrial Fibrillation Registry. Circulation 129:1568-1576

Olesen JB et al. (2012) Stroke and bleeding in atrial fibrillation with chronic kidney disease N Engl J Med 367:625-635

Piccini JP et al (2014) Relationship between time in therapeutic range and comparative treatment effect of rivaroxaban and warfarin: results from the ROCKET AF trial. J Am Heart Assoc 3:e000521

Pisters R, Lane DA, Nieuwlaat R, de Vos CB, Crijns HJ, Lip GY (2010) A novel user-friendly score (HAS-BLED) to assess 1-year risk of major bleeding in patients with atrial fibrillation: the Euro Heart Survey Chest 138:1093-1100

Potpara TS, Ferro CJ, Lip GYH (2018) Use of oral anticoagulants in patients with atrial fibrillation and renal dysfunction. Nat Rev Nephrol 14:337-351

Rosendaal FR, Cannegieter SC, van der Meer FJ, Briet E (1993) A method to determine the optimal intensity of oral anticoagulant therapy. Thromb Haemost 69:236-239

Usrds (2018) 2017 Annual Data Report Volume 1: chronic kidney disease. Cardiovascular disease in patients with chronic kidney disease. Am J Kidney Dis 71:S77-S94

Wallentin L et al (2013) Efficacy and safety of apixaban compared with warfarin at different levels of predicted international normalized ratio control for stroke prevention in atrial fibrillation. Circulation 127:2166-2176

Wallentin L et al (2010) Efficacy and safety of dabigatran compared with warfarin at different levels of international normalised ratio control for stroke prevention in atrial fibrillation: an analysis of the RE-LY trial. Lancet 376:975-983

Wysowski DK, Nourjah P, Swartz L (2007) Bleeding complications with warfarin use: a prevalent adverse effect resulting in regulatory action. Arch Intern Med 167:1414-1419

Zhang L et al (2019) Oral anticoagulation for atrial fibrillation thromboembolism prophylaxis in the chronic kidney disease population: the state of the art in 2019. Cardiovasc Drugs Ther 33:481-488

Zhang L et al (2008) Prevalence and factors associated with CKD: a population study from Beijing. Am J Kidney Dis 51:373-384

Zhong SL, Yu XY, Liu Y, Xu D, Mai LP, Tan HH, Lin QX, Yang M, Lin SG (2012) Integrating interacting drugs and genetic variations to improve the predictability of warfarin maintenance dose in Chinese patients. Pharmacogenet Genomics 22:176-182

Zhu J, Zhang W, Li Y, Zhang W, Wang H, Zheng W, Wang C (2010) ARMS test for diagnosis of CYP2C9 and VKORC1 mutation in patients with pulmonary embolism in Han Chinese. Pharmacogenomics 11:113-119

Publisher's note Springer Nature remains neutral with regard to jurisdictional claims in published maps and institutional affiliations. 